\title{
Quantitative sweat test in diabetics with neuropathic foot lesions
}

\author{
ME AHMED, PAMELA M LE QUESNE \\ From the Departments of Surgical Studies and Neurological Studies, The Middlesex Hospital Medical School, \\ London and MRC Toxicology Unit, Carshalton, Surrey, UK
}

SUMMARY The volume of sweat produced by axon reflex stimulation using acetylcholine was measured in one foot each of 35 control subjects and 52 feet of 37 diabetic patients ( 28 with neuropathic ulceration, 11 with Charcot arthropathy, nine with somatic neuropathy but no foot lesion and four with no evidence of somatic neuropathy). In controls, the volume of sweat was greater in males than females. A flare response was seen in $94 \%$ of control feet. In diabetics, the volume of sweat was within the control range in $17 \mathrm{feet}$, increased in one, reduced in seven, and absent in 27 . Sweating was absent in $75 \%$ of feet with a neuropathic ulcer; a flare response was absent in $86 \%$ of them. Sweating was only absent in $36 \%$ of feet with Charcot arthropathy and was increased in one, whereas the flare response was absent in all. Autonomic cardiovascular reflexes were more frequently abnormal than the sweat test; sweating was absent in only one patient with normal cardiovascular reflexes.

In recent years measurement of cardiovascular reflexes has added much to our knowledge of the frequency and severity of autonomic neuropathy in diabetics. ${ }^{1}$ Defects have been found to be more severe in the presence of somatic neuropathy ${ }^{2}$ and in those with foot ulceration. ${ }^{3-5}$ Fewer measurements have been made of autonomic function in the limbs largely because of the greater technical complexity of obtaining quantitative data.

Alteration of sweating in diabetics with autonomic neuropathy was noted as early as 1893 by Pryce. ${ }^{6}$ Rundles ${ }^{7}$ stressed that anhydrosis was common in the lower limbs. Absent thermal sweating ${ }^{8}$ and abnormalities of galvanic skin resistance have been taken to indicate defective sudomotor function. ${ }^{9}$ The incidence of defective sweating is greater when neuropathic ulcers are present. ${ }^{3}$ Methods for more direct quantitation of the sweat output have been described recently. Kennedy $e t \mathbf{a l}^{10}$ demonstrated in diabetics a reduction of sweat output and the number of active

Address for reprint requests: Dr PM Le Quesne, The Middlesex Hospital, London WIN 8AA, UK.

Received 26 July 1985 and in revised form 20 November 1985. Accepted 23 November 1985 sweat glands in response to local electrophoresis of pilocarpine. They ${ }^{11}$ found that the defect correlated better with loss of pain appreciation which, like sweating, is a function dependent on small nerve fibres, than large fibre function such as vibration perception and motor nerve conduction velocity.

Low et $a l^{12}$ have described a quantitative method of measuring sweat output stimulated via an axon reflex in response to electrophoresis of acetylcholine into nearby skin. They found reduced or absent sweating in patients with peripheral neuropathy due to a variety of causes. We have used this technique in a series of diabetic patients with neuropathic ulcers of the feet and/or Charcot arthropathy to provide further information about the state of the autonomic nervous system in these conditions.

\section{Patients and methods}

Control measurements were made on one foot each of 35 volunteers from the hospital staff or in patients with no obvious neurological disease. All had normal appreciation of pin prick and vibration sensation, and ankle tendon reflexes were present. Twenty-three were males aged 26-75 years (mean $44 \mathrm{SD}-13.8) ; 12$ were females aged 20-53 years (mean $36 \mathrm{SD}-12 \cdot 6$ ). 
Thirty-seven diabetic patients were studied ( 27 male, aged 27-73 years and 10 female, aged 25-78 years); both feet were tested in 15 making a total of 52 feet. Thirteen feet had neither ulcers nor Charcot arthropathy, although there was evidence of somatic neuropathy in nine of them (absent ankle reflexes and absent vibration sensation at the toes and also at the malleoli in some). The remaining patients were divided into two groups:

(a) ulcer group: Neuropathic ulcers were present in 28 feet (14 active, 14 healed, none was acutely infected). None had arthropathy. (b) arthropathy group: Charcot arthropathy, as shown by clinical deformity of the foot with radiological evidence of bone destruction at the mid-tarsal joint, was present in 11 feet, with ulceration over the tarsal deformity in seven.

Of the 15 patients in whom both feet were tested, 10 had similar lesions on the two feet, two had an ulcer on one side and arthropathy on the other, whereas three with unilateral ulcer or arthropathy had somatic neuropathy without a foot lesion on the other side.

\section{Procedure}

A quantitative sudomotor axon reflex test was carried out as described by Low et al $^{\mathbf{1 2}}$ using apparatus built at the Mayo Clinic. Patients were examined in a room at a constant temperature of $26^{\circ} \mathrm{C}$. The foot temperature was kept at $30-32^{\circ} \mathrm{C}$ by blowing hot air over it if necessary. A sweat capsule, $2 \mathrm{~cm}$ diameter, with three concentric compartments was placed on the skin on the dorsum of the foot over the lateral three metatarsal bones and held in position with a rubber band. The outer of the three compartments of the capsule was filled with $10 \%$ acetylcholine, which was electrophoresed into the skin by passing a constant current of $1 \mathrm{~mA}$. The anode was a plate on another part of the foot, the skin under the anode being prepared by gentle abrasion. The resistance between the two electrodes was always made to be less than $200 \mathrm{k} \Omega$. With higher resistances sweating was sometimes absent in control subjects.

The middle chamber of the capsule provided an air gap and sweat was collected from the inner chamber, which was $1 \mathrm{~cm}$ in diameter. Dry nitrogen was blown through the inner capsule at a constant flow rate of $80 \mathrm{ml} / \mathrm{min}$. The gas temperature was then adjusted to $40^{\circ} \mathrm{C}$ in a heat controlled block containing a humidity sensor. The output of the sensor was plotted on a chart recorder with simultaneous integration of the area under the curve.

There was always a latent period of 2 to 5 minutes from the start of stimulation until the onset of sweating. Stimulation was continued for 8 minutes after the onset of sweating indicated by an increase in humidity, and recording was continued for a further 5 minutes after stimulation ceased. The humidity curve had rarely returned to the base line at the end of the recording period, and the sweat volume recorded was the amount of sweat evaporating into the dry nitrogen during the test period and did not represent the total sweat output produced by the axon reflex stimulation.

The system was calibrated by injecting known volumes of water onto a small filter paper attached to the inner compartment and recording the humidity to total evaporation. A graph of the integrated chart recording for different volumes was plotted for calculation of sweat volume.
Autonomic cardiovascular reflex tests

Two tests of cardiovascular autonomic function (the heart rate response to the Valsalva manoeuvre and to a single deep breath) were carried out on 24 diabetics: three without ulcers or arthropathy, 14 with ulcers on one or both sides, five with arthropathy on one or both sides and two with an ulcer on one side and arthropathy on the other. For the Valsalva ratio, a value less than 1.2 was taken as abnormal. ${ }^{5}$ For heart rate variability during a deep breath, a difference of less than 10 beats/min was considered abnormal. ${ }^{5}$

\section{Results}

\section{Control subjects}

Axon reflex sweating occurred in all subjects. Mean sweat volume was significantly greater in males $(2.48$ $\mu$ l SD 0.63$)$ than in females $(1.75 \mu$ l SD 0.73$)(t<$ 0.05 ) (fig). However, there was no correlation with age for either sex. For males, the correlation coefficient (r) was $-0.197(p>0.05)$ and for females $r=0.269(\mathrm{p}>0.05)$.

Repeat tests were performed on six feet. Sweat volume varied from $1.48 \mu \mathrm{l}$ to $3.7 \mu \mathrm{l}$ in different individuals, the greatest difference between two readings in the same subject being $0.2 \mu \mathrm{l}$.

Since some diabetic feet have a higher resting skin temperature than many normal feet, the effect of temperature rise alone was studied. No spontaneous sweating occurred when the skin temperature was raised to $34^{\circ} \mathrm{C}$. In two subjects skin temperature was raised to $36^{\circ} \mathrm{C}$ before the test. Axon reflex sweat volume was increased by $0.2 \mu \mathrm{l}$ in one subject and reduced by $0.2 \mu \mathrm{l}$ in the other compared with the

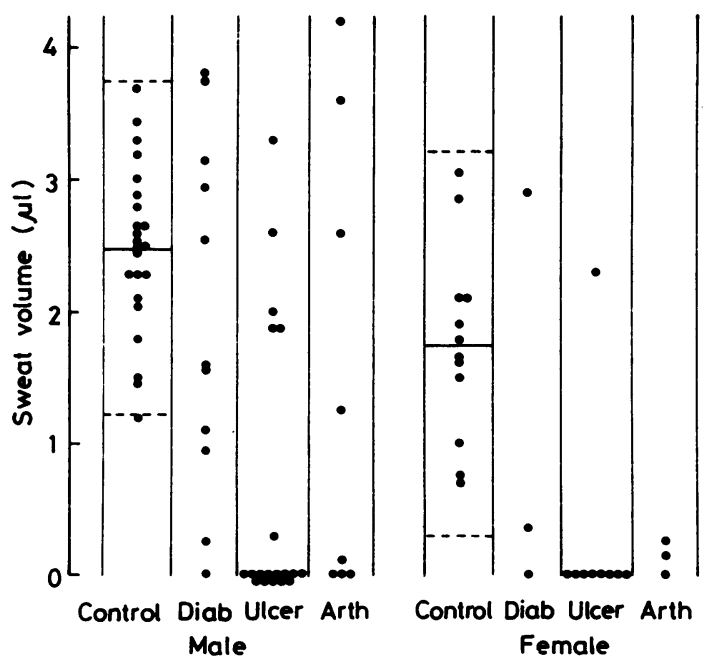

Fig Volume of sweat produced by axon reflex stimulation in male and female control subjects and groups of diabetic subjects. 
volume when skin temperature was $30-31^{\circ} \mathrm{C}$. Electrophoresis of normal saline did not stimulate sweating.

Following electrophoresis of acetylcholine a flare response occurred around the test area in 33 of 35 control subjects.

\section{Diabetic subjects}

Sweating was absent in 27 of the 52 feet tested, reduced in seven, within the control range in 17 and increased in one. The distribution in the different groups is shown in the fig and table. A flare response was absent in a high proportion of subjects in each of the diabetic groups (table).

Symmetrical results were obtained in 13 of the 15 patients in whom both feet were examined. In the other two, both of whom had bilateral ulcers, sweating was absent on one side and normal on the other.

In the ulcer group, both sweating and flare were absent in a high proportion, whereas in those with arthropathy flare was absent in all, but sweating only in one third (table).

In two patients with arthropathy sweat volume was at or above the upper limit of the control range. One patient with arthropathy gave an interesting history of excessive sweating of her feet several years previously, at the time she was developing arthropathy. For a few years prior to the sweat test she had had dry feet, even in hot weather; no axon reflex sweating could be induced.

Four patients in the ulcer group and six patients with arthropathy but no control subjects, had a resting foot skin temperature of $33^{\circ} \mathrm{C}$ or above, despite the absence of overt sepsis in any of the feet. The high foot temperatue is a likely consequence of vasomotor denervation, but sweating was normal or increased in six.

Measurement of autonomic cardiovascular reflexes are available for comparison with the sweat test in 36 feet from 24 subjects. One or both cardiovascular reflexes were abnormal for 30 of them. Sweating was normal in seven of these and abnormal in 23. Where cardiovascular reflexes were normal, sweating was also normal in five feet and absent in only one. Thus, cardiovascular reflexes were more frequently abnormal than sweating.

Table Percentage of control subjects and diabetic patient with absent sweating or flare response

\begin{tabular}{lllc}
\hline & $n$ & Sweat absent & Flare absent \\
\hline Control & 23 & $0 \%$ & $6 \%$ \\
No ulcer or arthropathy & 13 & $15 \%$ & $77 \%$ \\
Ulcer group & 28 & $75 \%$ & $86 \%$ \\
Arthropathy group & 11 & $36 \%$ & $100 \%$ \\
\hline
\end{tabular}

\section{Discussion}

The volume of sweat produced by axon reflex stimulation under standard conditions gives a good indication of the state of sudomotor innervation in the limb tested. The test has been shown to be highly reproducible in the same individual. Absent sweating is an indication of peripheral denervation. Denervated sweat glands do not respond to direct stimulation with acetylcholine, ${ }^{1314}$ although in the test used here stimulation is via an axon reflex which obviously requires the integrity of sudomotor nerve fibres.

This study, showing a marked impairment of sweat production in response to reflex stimulation by acetylcholine in the great majority of patients with diabetic peripheral neuropathy, confirms the frequency of impairment of peripheral autonomic function in this condition. Of greater interest was the finding that one patient with severe arthropathy had an abnormally high sweat output and another produced a volume near the upper limit of the control range. These findings are particularly notable since it has been suggested that vasomotor denervation, resulting in arteriovenous shunting and increased blood flow through the foot, may be of aetiological importance in the development of arthropathy. ${ }^{15}$ It would be of interest to determine whether there is a dissociation of vasomotor and sudomotor function in these subjects. It is a recognised, but poorly documented, clinical observation that some diabetics have increased spontaneous sweating in their feet at some stage in their disease, as indeed did one of our patients and our observations provide quantitative confirmation of this phenomenon. They are in conformity with the observation of Ozeran et al, ${ }^{9}$ who, on the basis of galvanic skin resistance measurements in the feet, demonstrated that both hyper- and hypoactivity of the autonomic system could occur in diabetics. It is of interest to note that two patients in the diabetic group, one with demonstrable somatic neuropathy, had a sweat output at the extreme upper end of the control range, suggesting that the phenomenon of autonomic hyperactivity may be more common than is generally realised, and that it may even be one of the earliest signs of neuropathy.

The cause of the phenomenon is not clear. Kennedy et al $^{16}$ have shown, in mice, that partial denervation is associated with extensive collateral sprouting of surviving autonomic nerves, resulting in each fibre inervating up to five times as many sweat glands as normal. Such a phenomenon occurring in the early stages of diabetic neuropathy could result in an increase in volume of sweat secretion via the axon reflex.

The flare response was first shown by Lewis ${ }^{17}$ to be an axon reflex and is thought to involve unmyelinated 
afferent, probably nociceptive, nerve terminals. ${ }^{18}$ Such terminals are likely to be stimulated by electrophoresed acetylcholine and it is probable that the same nerves were involved in the present study as in the classical flare response to noxious stimulation and intradermal histamine. The high incidence of absent flare response in diabetics is not surprising in view of the predominant involvement of small nerve fibres in many patients with diabetic neuropathy. ${ }^{19} 20$

The role of disturbed autonomic function as one important factor in the genesis of foot complications of diabetes has been stressed in recent years. ${ }^{21}$ Lack of sweating has been thought to contribute to the development of neuropathic ulcers and the incidence of this finding was high in the present series, as has been found by others. ${ }^{322}$ The absence of a flare response in all feet with arthropathy underlines the importance of degeneration of unmyelinated nociceptive afferent nerve fibres in the genesis of this condition.

During the performance of this work MEA held a Fellowship awarded by the Wellcome Trust. The apparatus used in the study was obtained with a grant from The Sir Jules Thorn Charitable Trust, to whom we are grateful. The sweat test apparatus was constructed for us by The Mayo Clinic, and we are indebted to Dr PA Low for his assistance in this. We would also like to thank Dr J Tappin for his help with establishing the technique and Mr T Gajree for technical assistance; also Dr A Kurtz, The Middlesex Hospital and Mr K Robertson, The London Foot Hospital for allowing us to investigate patients under their care, and Professor LP Le Quesne for helpful criticism and advice.

\section{References}

${ }^{1}$ Ewing DJ, Clarke BF. Diagnosis and management of diabetic autonomic neuropathy. $\mathrm{Br}$ Med $J$ 1982; 285:916-18.

${ }^{2}$ Ewing DJ, Burt AA, Williams IR, Campbell IW, Clarke BF. Peripheral motor nerve function in diabetic autonomic neuropathy. J Neurol Neurosurg Psychiatry 1976;39:453-60.

${ }^{3}$ Deanfield JE, Daggett PR, Harrison MJG. The role of autonomic neuropathy in diabetic foot ulceration. $J$ Neurol Sci 1980;47:203-10.

${ }^{4}$ Edmonds ME, Nicolaides K, Watkins PJ. The importance of autonomic neuropathy in the aetiology of diabetic neuropathic foot. Diabetologia 1981;21:506.

${ }^{5}$ Ahmed ME, Delbridge L, Le Quesne LP. The role of autonomic neuropathy in diabetic foot ulceration. $J$ Neurol Neurosurg Psychiatry (In press).

${ }^{6}$ Pryce TD. On diabetic neuritis, with a clinical and pathological description of three cases of diabetic pseudotabes. Brain 1893;16:416-24.

${ }^{7}$ Rundles W. Diabetic neuropathy. Medicine 1945;24: 111-60.

${ }^{8}$ Low PA, Walsh JC, Huang CY, McLeod JG. The sympathetic nervous system in diabetic neuropathy - a clinical and pathological study. Brain 1975;98:341-56.

${ }^{9}$ Ozeran RS, Wagner GR, Reimer TR, Hill RA. Neuropathy of the sympathetic nervous system associated with diabetes mellitus. Surgery 1970;68:953-8.

${ }^{10}$ Kennedy WR, Sakuta M, Sutherland D, Goetz FC. Quantitation of the sweating deficiency in diabetes mellitus. Ann Neurol 1984;15:482-8.

${ }^{11}$ Kennedy WR, Sakuta M, Sutherland D, Goetz FC. The sweating deficiency in diabetes mellitus: methods of quantitation and clinical correlation. Neurol (Cleveland) $1984 ; 34: 758-63$.

${ }^{12}$ Low PA, Caskey PE, Tuck RR, Fealey RD, Dyck PJ. Quantitative sudomotor axon reflex test (Q-SART). Ann Neurol 1983;14:573-80.

${ }^{13}$ Coon JM, Rothman S. The sweat response to drugs with nicotine-like action. J Pharmacol Exp Therap 1941; 73:1-11.

${ }^{14}$ Collins KJ, Weiner JS. Axon reflex sweating. Clin Sci 1961;21:333-44.

${ }^{15}$ Watkins PJ, Edmonds ME. Sympathetic nerve failure in diabetes. Diabetologia 1983;25:73-7.

${ }^{16}$ Kennedy WR, Sakuta M. Collateral reinnervation of sweat glands. Ann Neurol 1984;15:73-8.

${ }^{17}$ Lewis T. The Blood Vessels of the Human Skin and their Responses. London: Shaw \& Sons, 1927.

${ }^{18}$ Celander O, Folkow B. The nature and the distribution of afferent fibres provided with the axon reflex arrangement. Acta Physiol Scand 1953;29:359-70.

${ }^{19}$ Said G, Slamma G, Selva J. Progressive centripetal degeneration of axons in small fibre diabetic polyneuropathy. Brain 1983;106:791-807.

${ }^{20}$ Guy RJC, Clark CA, Malcolm PN, Watkins PJ. Evaluation of thermal and vibration sensation in diabetic neuropathy. Diabetologia 1985;28:131-7.

${ }^{21}$ Delbridge L, Ctercteko G, Fowler C, Reeve TS, Le Quesne LP. The aetiology of diabetic neuropathic ulceration of the foot. Br J Surg 1985;72:1-6.

22 Boulton AJM, Hardisty CA, Betts RP, et al. Dynamic foot pressure and other studies as diagnostic and management aids in diabetic neuropathy. Diabetes Care 1983;6:26-33. 